\title{
Implied volatility indices: A review and extension in the Turkish case ${ }^{\text {it }}$
}

\author{
Ahmet Sensoy*, John Omole \\ Bilkent University, Faculty of Business Administration, Ankara 06800, Turkey
}

\section{A R T I C L E I N F O}

\section{Keywords:}

VIX

Implied volatility

Options market

Emerging markets

Market microstructure

JEL classifications:

F30

G13

G14

\begin{abstract}
A B S T R A C T
We re-visit the model-free methodology of the new VIX, and review how its counterparts are estimated empirically across the world. Then, we modify its parameter selection procedure for it to be compatible with the microstructure characteristics of emerging derivatives markets. Applying this approach on Turkish market data, we introduce VBI; the implied volatility index of Borsa Istanbul. Accordingly, (i) VBI is a strong predictor of the future realized volatility, (ii) it is significantly correlated with Turkey's own financial indicators, but not with many global financial indicators, (iii) there is an implied volatility spillover from US equity market to Borsa Istanbul, but not the other way around.
\end{abstract}

\section{Introduction}

In 1993, Chicago Board Options Exchange (CBOE) introduced the volatility index (VIX) to measure market volatility implied by at the money S\&P100 Index option prices. The aim was to introduce a forward-looking volatility measure, unlike historical volatility. Since its introduction, it has become a benchmark for the ex-ante volatility in the stock market and even regarded as the "investor fear gauge" in financial markets (Whaley, 2000).

The original construction of VIX uses the data of S\&P100 Index options to compute an average of the Black-Scholes option implied volatility with strike prices close to the current spot index level and maturities interpolated at about one month. In 2003, the CBOE revised the calculation of the VIX due to both theoretical and practical considerations. S\& P500 Index replaced S\&P100 Index as the underlying asset to represent the equity market better. Furthermore, the methodology was modified to measure the weighted average of option prices across all strikes at two nearby maturities within a model-free scheme (Carr \& Wu, 2006).

Using the new methodology, the $\mathrm{CBOE}$ later introduced several other implied volatility indices with different underlyings such as VXN (NASDAQ volatility index), VXD (DJI volatility Index) and RVX (Russell 2000 volatility index). After successful implementation of the new methodology, other exchanges around the world have also created a new series of implied volatility indices, including VDAX (Germany), VCAC (France), and VFTSE (UK). ${ }^{1}$
Although the construction of this new methodology is straightforward, its empirical estimation is not. The reason behind this is the free selection of several empirical parameters and rules such as the calculation frequency, reference option prices, forward price levels, risk-free rates, option filters and roll-over times. In this study, we first show how this index is constructed in theory and review its estimation process for the most popular ones across the world. Then, we try to construct the index for one of the leading emerging markets, Turkey, where there is no official implied volatility index. In order to construct it, we adapt the parameter selection process to be suitable for Turkish derivatives market microstructure whose main characteristics are significantly different from those of the developed markets under consideration, especially due to options market illiquidity. After constructing the implied volatility index, we examine its time series characteristics, its contemporaneous and lagged relation with domestic and global financial indicators, and whether it adds value in terms of forecasting realized volatility.

Our study is in line with the works by Siriopoulos and Fassas (2012) and Bugge, Guttormsen, Molnar, and Ringdal (2016) which introduce the implied volatility indices for the Greek and the Norwegian stock markets respectively using the new $\mathrm{CBOE}$ methodology. Siriopoulos and Fassas (2012) show that Greek implied volatility is negatively correlated with its underlying index and it contains information about future realized volatility. Moreover, they show that there is a unidirectional implied volatility transmission from German and U.S. stock

\footnotetext{
A part of this work was completed while the corresponding author was working at the Derivatives Market of Borsa Istanbul.

* Corresponding author.

E-mail address: ahmet.sensoy@bilkent.edu.tr (A. Sensoy).

${ }^{1}$ The list of most popular implied volatility indices calculated by the new VIX methodology can be found in the Appendix.
} 
markets to Greek stock market. Bugge et al. (2016) compare Norwegian implied volatility to VIX and VDAX, and show that it has similar characteristics with the latter two. Similar to the findings of Siriopoulos and Fassas (2012), they also show that Norwegian implied volatility index significantly improves forecasting future realized volatility. ${ }^{2}$

In this work, we find that our implied volatility index (VBI) improves forecasting future realized volatility. ${ }^{3}$ Even after controlling for past realized volatility, it still has strong explanatory power. Analysing its contemporaneous relation with several financial variables shows us that VBI is significantly correlated with Turkey's own financial indicators with the expected sign of correlations, whereas this significance mostly disappears when we consider global financial indicators. Further, we investigate the implied volatility spillovers among the U.S., eurozone and Turkish equity markets as proxied by VIX, V2X and VBI respectively. Accordingly, shocks to the VIX have unidirectional significant spillover effects on the implied volatilities of eurozone and Turkish equity markets in the same direction. Interestingly, V2X has no such significant effect on VBI. Finally, shocks to the VBI has no significant effect on other implied volatilities as expected.

The rest of the paper is organized as follows: Section 2 explains how VIX is constructed in theory and presents the differences in estimation procedures across several exchanges around the world. Section 3 suggests the ideal parameters to estimate the implied volatility index of Borsa Istanbul. Section 4 describes the data and contains the main empirical analysis. Finally, Section 5 concludes.

\section{Construction and estimation of the new VIX}

In this section, we present how VIX is constructed in theory and the parameters needed to estimate VIX empirically.

\subsection{Construction}

As stated by the CBOE (2003), new VIX depends on the following formula

$\sigma^{2}=-\frac{1}{T}\left(\frac{F}{K_{0}}-1\right)^{2}+\frac{2}{T}\left[\sum_{i=1}^{N} \frac{\delta K_{i}}{K_{i}^{2}} e^{R T} Q\left(K_{i}\right)\right]$

then the implied volatility of an option chain is equal to $\sigma$, where $T$ is time to expiration, $F$ is forward index level, $K_{0}$ is the first strike below the forward index level, $K_{i}$ is the strike price of the $i^{\text {th }}$ out-of-the-money option (a call $K_{i}$ if $K_{i}>K_{0}$ and a put if $K_{i}<K_{0}$; both put and call if $K_{i}=K_{0}$ ), $\delta K_{i}$ is the interval between strike prices-half the difference between the strike on either side of $K_{i}$ given by the following:

$\delta K_{i}=\frac{K_{i+1}-K_{i-1}}{2}$.

Note that $\delta K$ for the lowest strike is simply the difference between the lowest strike and the next higher strike. Similarly, $\delta K$ for the highest strike is the difference between the highest strike and the next lower strike. Finally, $R$ is the risk-free rate to expiration and $Q\left(K_{i}\right)$ is the option price with strike $K_{i}$.

Formula in Eq. (1) is applied to near-term (options with closest time to maturity) and next-term (options with second closest time to maturity) options to get the $\sigma_{1}^{2}$ and $\sigma_{2}^{2}$ respectively. Then, $\sigma_{1}^{2}$ and $\sigma_{2}^{2}$ are interpolated using time to expirations $T_{1}$ and $T_{2}$ to get a single parameter $\tilde{\sigma}^{2}$. Finally, the model-free implied volatility index VIX is calculated as $100 \times \tilde{\sigma}$.

\footnotetext{
${ }^{2}$ See also the works by Tzang, Hung, Wang, and Shyu (2011) and GonzalezPerez and Novales (2011) for the introduction of implied volatility indices for Taiwan and Spain respectively.

${ }^{3}$ VBI stands for the "Volatility of Borsa Istanbul".
}

\subsection{Parameter selection}

Although the methodology behind VIX has been highly standardized, some deviations naturally arise from institutional features, liquidity concerns or historical conventions. In this part, we document these differences and their reasonings. ${ }^{4}$

\subsubsection{Option price $Q\left(K_{i}\right)$ and index calculation frequency}

There are various alternatives at this stage including but not limited to: (i) midpoint of the bid-ask price of the last quote on options; (ii) last trade price; (iii) average of all trading prices, and (iv) settlement price as a proxy for the $Q\left(K_{i}\right)$. For example, CBOE's VIX uses mid-quote prices. Interestingly, it is not a strict rule to use only one of the methods above. In the case of Japan (VXJ), these items are ordered according to a priority and option prices are calculated following that order depending on availability of the data. For VXJ, the first three choices (in order) are the last trade price in the last $15 \mathrm{~s}$, last mid-quote in the last $15 \mathrm{~s}$ and the last trade price before the last $15 \mathrm{~s}$, all depending on the availability. After that, different alternatives are considered. On the other hand, implied volatility index of Korea (VKOSPI) uses the last trading price as a priority. If the listed options are not enough, the option prices are estimated by the Black and Scholes (1973) model, different than the alternatives above.

In this selection, there are three potential advantages for the use of mid-quote prices over realized trading prices (Areal, 2008). First, a trade originated by a bid (ask) quote following a trade originated by an ask (bid) quote might create jumps in the option prices. Thus, using mid-quotes reduces this bouncing. Second, there is more data on quotes than on trades so information will be reflected faster in this dataset than those in trades. This is especially important if the index is to be estimated at a high frequency. Third, the next-term's option chain might suffer from illiquidity in terms of trades, however the order book has more liquidity in terms of order updates. Thus, there is information in the order book that is not reflected in the traded prices hence mid-quote prices reduces the effect of missing data.

The methods above are frequently used for the liquid options markets and the corresponding indices are calculated frequently within the day, ranging from $5 \mathrm{~s}$ to $1 \mathrm{~min} .{ }^{5}$ However, it is clear that they would not work when the option market suffers from illiquidity in terms of both trades and quotations. In that case, one of the first things to consider is the estimation frequency. In such an illiquid market, it is possible that frequent intraday estimations might not be realized. One can think of using the last known option prices (or quotes) until the new data is available (as in the case of Hong Kong - VHSI), bearing in mind that the index might be stale for a very long time. ${ }^{6}$ In order to prevent having a stale index for a long time, a limit on duration of inactivity can be imposed or natural cubic splines can be employed in order to curvefit the option prices for artificial option pricing, as is the case in India (NIFVIX).

Serious illiquidity concerns lead Siriopoulos and Fassas (2012) to estimate the Greek implied volatility index at a daily frequency and to

\footnotetext{
${ }^{4}$ The technical information presented in this sub-section is collected from the white papers that explain the details of calculating the relevant implied volatility indices. These documents are available for download on the stock exchanges' websites.

${ }^{5}$ For example, VKOSPI and VHSI are calculated for every $30 \mathrm{~s}$, whereas VXJ is calculated at $15 \mathrm{~s}$ frequency. For others, see Table 1.

${ }^{6}$ In addition to this case, Hong Kong stock exchange takes special caution for high volatile market situations. In particular, if VHSI shows a tick-by-tick movement (either up or down) of more than $5 \%$ from the last disseminated index value, such calculated index value will be regarded as abnormal and will not be disseminated, and the last disseminated index value will be used. If such abnormal index value persists for four consecutive ticks, it will be regarded as normal and will be disseminated. This treatment for abnormal index values will not be applied to the first and last index ticks of each trading session.
} 
use end-of-day settlement prices for the option prices. The advantage is that a settlement price is calculated based on an algorithm (in essence a weighted average) and are less prone to manipulation or imprecision. Moreover, whether there is no trade nor a quote on a given day, settlement prices still have to be calculated and disseminated by the stock exchange since they are used in daily marked-to-market margin level calculations.

\subsubsection{Forward index price $F$}

A few alternatives also exist at this stage. For example, CBOE determines the forward index level by using the put-call parity for at-themoney strike. However, this approach is accurate and robust only if the measurement errors for the quote midpoint of the at-the-money options are small and the quotes are current. Instead, a wider set of put-call option pairs may be used to determine the forward rate in a more robust, albeit also less precise manner, as noted in the Eurex regulations (Andersen, Bondarenko, \& Gonzalez-Perez, 2015). At this stage, an interesting approach comes from the Indian stock exchange in which they use observed futures prices for the underlying asset in lieu of the forward price. The exchange states that they have an actively traded, very large and liquid index futures market. Therefore they consider the latest available trade price of the NIFTY futures of the respective expiry month as the forward index price.

\subsubsection{Risk-free rate $R$}

The risk-free rate is the theoretical return rate of an investment with zero risk. In the implied volatility index estimations, this rate is used for discounting the option pay-offs. CBOE interpolates these rates from U.S. Treasury bill rates. On the other hand, several others rely on the interpolation of interbank rates which reflect the costs of unsecured borrowing for major financial institutions. For a liquid bond market, weighting the treasury bill rates works well. However, if the market is illiquid, interpolated rates could be misleading. In such cases, using the interbank rates seems a better choice since banks give big amount of loans to each other frequently and this rate is announced on a daily basis in the interbank market.

Since VIX methodology is mostly applied for shorter maturities (30 days), this difference has a negligible impact, but for volatility indices covering longer maturities and during periods of financial stress with elevated gap between interbank and treasury rates, the difference can become meaningful (Andersen et al., 2015).

\subsubsection{Range of strike prices $K_{i}$}

To obtain realistic values, not all options are included in the VIX estimation and a certain cut-off rule is employed. CBOE applies a strict stopping rule centered on the at-the-money strike; moving into the outof-the-money region, all options with positive bid quotes are included until two consecutive zero bid quotes are encountered, after which all further out-of-the-money options are excluded. This alleviates the noise stemming from low-priced and illiquid options, but it also induces randomness in the effective strike range (Andersen et al., 2015). In practice, employing this rule in an illiquid options market is almost impossible.

Alternatively, Eurex eliminates options with a mid-quote below $€ 0.5$, whereas Hong Kong uses only out-of-the-money options with exercise prices within $20 \%$ of the at-the-money strike price, which is an example of an inflexible corridor implied volatility index. For other exchanges with illiquid options market, all quoted options are allowed to contribute. ${ }^{7}$

\footnotetext{
${ }^{7}$ According to $\mathrm{Wu}$ and Liu (2018), letting the strike prices to span the full range might bring estimation errors in VIX. They propose a way to estimate the resulting truncation error using corridor variance swaps. Alternative adjusting schemes are also proposed by Grover and Thomas (2012). In the case of using settlement prices instead of trade prices or mid-quotations as a proxy for $Q\left(K_{i}\right)$, these approaches become of less interest.
}

\subsubsection{Option filters}

If exchanges have strict restrictions on the range of strike prices, then they typically apply only soft additional filtering rules. For example, only additional constraint by the CBOE is the exclusion of any remaining options with a zero bid quote. Eurex imposes a maximum spread rule that forces the quotation levels within a practical valid range (Andersen et al., 2015). However, this range is not constant and depends on both the underlying index level and market conditions. For example, if Eurex activates "Fast Market" status, permitting marketmakers to increase their quotation spreads under very turbulent trading conditions, maximum spreads are set higher accordingly, with the applicable filter criteria being adjusted accordingly.

On the contrary, some exchanges allow all options to enter the index computation, but indirectly eliminate illiquid or low-priced options via a maximum percentage spread rule in order to induce random variation in the option price range. For example, Hong Kong stock exchange stipulates that the ask quote can not be lower than the bid quote. The remaining differences are mostly due to institutional features.

\subsubsection{Roll-over times}

In the U.S. market, every month is an expiry month for index options. CBOE uses put and call options in the nearest and next-nearest expiration months in order to capture a 30-day calendar period. When those options have 8 days left to expiration, estimations are rolled to the next second and third contract months in order to minimize pricing anomalies that might occur close to expiration.

Up to this point, we have made it clear that option liquidity is essential to properly estimate implied volatility, and a common problem of emerging options markets is the illiquid trade for the second-nearby month options, not to mention the third-nearby month options. In practice, active traders are mainly realized on nearby month options, and the trades of the second-nearby month options will become active only when nearby options are very close to expiry. If next-nearby month options are too illiquid, the estimation errors due to structural noises could be amplified in case the roll-over times are long (Tzang et al., 2011).

Indian and Hong Kong stock exchanges roll-over when 3 trading days remain to expiry while Australian and Korean exchanges prefer 5 calendar and 4 business days, respectively. However, Korean exchange uses only nearest month options when its residual maturity is longer than 30 days after the roll-over. Gonzalez-Perez and Novales (2011) suggest to use 3 calendar days for a theoretical Spain VIX. For the Greek market, which is an illiquid options market, Siriopoulos and Fassas (2012) suggest that options of the first month should be used until the very last day of their life. Put together, the literature suggests that rollover times should be short as liquidity reduces.

Finally, we end this part with the summary of abovementioned explanations. Table 1 presents various implied volatility indices across the world and the main differences in their calculations.

\section{Model suggestion for Borsa Istanbul}

In this section, we provide suggestions for parameter selection to estimate the implied volatility index of Borsa Istanbul (hereafter VBI). Options Market of Borsa Istanbul was launched on December 21, 2012 and only single stock options were traded initially. In August 2013, the product range widened to include options written on the benchmark index, BIST30. Trading is done on a multiple price, continuous auction method in which the orders match automatically based on a price-time priority.

The expiry dates are the last trading days of February, April, June, August, October and December. Contracts with three different nearest maturity dates to the current month are available for trading. If December is not one of those expirations, an extra contract with an expiration of December is also launched. As evident from these maturity months, VBI is set to measure the implied volatility of 60-day 
Table 1

Main differences in the estimation of popular implied volatility indices.

\begin{tabular}{|c|c|c|c|c|c|c|}
\hline Country/Exchange & Frequency & Forward Index $F$ & Risk-free $R$ & Range of strike prices $K_{i}$ & Option remove filter & Roll-over times \\
\hline СBOE & $15 \mathrm{~s}$ & Cond. (1) & Cond. (2) & Cond. (3) & Cond. (4) & 8 calendar days \\
\hline Canada & $1 \mathrm{~min}$ & Cond. (1) & CORRA/CDOR & Cond. (3) & Cond. (4) & 5 calendar days \\
\hline Germany & $1 \mathrm{~min}$ & Cond. (1.1) & EONIA/EURIBOR & $\min (Q)$ & Cond. (4), $\mathrm{A}=0$, MS & 2 calendar days \\
\hline Switzerland & $1 \mathrm{~min}$ & Cond. (1.1) & LIBOR & $\min (Q)$ & Cond. (4), A=0, MS & 2 calendar days \\
\hline Eurex & $5 \mathrm{~s} / 1 \mathrm{~min}$ & Cond. (1.1) & EONIA/EURIBOR & $\min (Q)$ & Cond. (4), A=0, MS & 2 calendar days \\
\hline Euronext & $5 \mathrm{~s}$ & Cond. (1.1) & LIBOR/EURIBOR & All allowed & Cond. (4), RS > 50\% & NA \\
\hline Australia & End of day & Cond. (1) & RBA BBSW & All allowed & Cond. (4) & NA \\
\hline Hong Kong & $30 s$ & Cond. (1) & HIBOR & {$\left[0.8 K_{0}, 1.2 K_{0}\right]$} & Cond. (4), B $\geq A$ & 3 trading days \\
\hline India & NA & Index Futures & NSE MIBOR & All allowed & Cond. (4), RS > 30\% & 3 trading days \\
\hline
\end{tabular}

Note: Conditions (1)-(4) and the other restrictions are defined as the following:

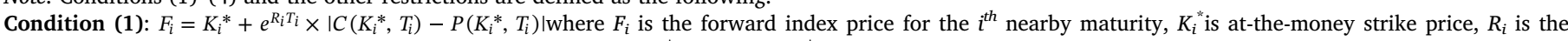

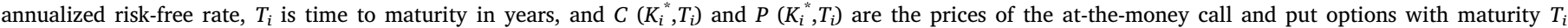
respectively. CBOE defines at-the-money strike level $K_{i}^{*}$ as the one which minimizes the distance between the call and put price.

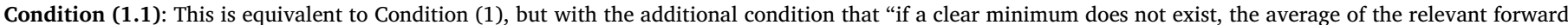
prices will be used instead" to determine $F_{i}$.

Condition (2): The annualized yield of the interpolated Treasury bills maturing closest to the expiration dates of the relevant options.

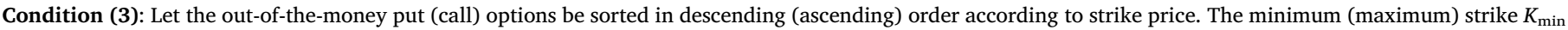

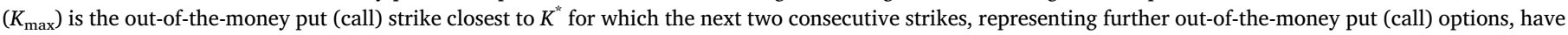
zero bid quotes.

Condition (4): Delete any remaining out-of-the-money options with zero bid prices.

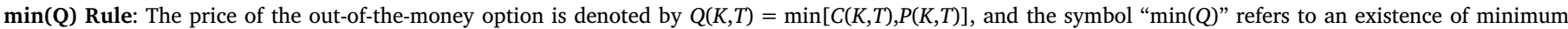
option price rule for inclusion in the computation.

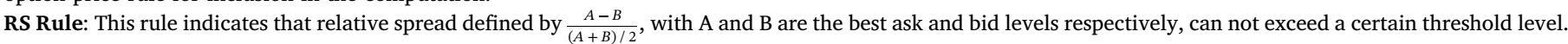
MS Rule: This rule indicates that maximum spread $|A-B|$ can not exceed a certain threshold level where A and B are the best ask and bid levels respectively.

ahead calendar period, unlike many others.

Our sample period to estimate VBI spans the trading days between October 1, 2013 and February 28, 2017. During this period, index options market has been illiquid most of the time. On some days, there are few trades and in some cases, bid-ask quotes are not available for an adequate number of strike prices. Therefore, we select our proxies considering this scenario. ${ }^{8}$

- Option Prices $Q\left(K_{i}\right)$ and index calculation frequency: VBI is calculated once at the end of the day using the settlement prices officially announced daily by the stock exchange after the trading period.

- Forward index price F: The index futures market of Borsa Istanbul is highly liquid. ${ }^{9}$ Therefore, last trade price of the BIST30 index futures contract with the same maturity date of the corresponding index option is a good proxy for the forward index price on a given day.

- Risk-free rate $R$ : At this stage, interpolation of the two closest interbank rates (TRIBOR) to maturity is preferred. The main reason is that its alternative, the weighted treasury bond rates, is not very suitable. At Borsa Istanbul, such treasuries are traded. However, even though the average daily trade volume is moderate at international standards, average number of trades in a given day is very low. On the other hand, Turkey has a very active interbank lending market which is suitable for selection as the risk-free return.

- Range of strike prices $K_{i}$ : Since we use the settlement prices, we do not have any concern on availability of the quotes nor the quotation

\footnotetext{
${ }^{8}$ Indeed, for an implied volatility index to be accurate, option market is desired to have at least a certain amount of liquidity. When CBOE first introduced VIX, there was already an active and highly developed index options market in the U.S. for almost ten years. For example, Korea introduced index options in 1997 but launched the corresponding implied volatility index in 2009. Similar situations are also observed in India (option introduction: 2000 — index launch: 2008), Taiwan (option introduction: 2001 - index launch: 2006) and Russia (option introduction: 2005 — index launch: 2010).

${ }^{9}$ According to the World Federation of Exchanges, BIST30 Index Futures is the 8th most liquid index futures contracts in the world. For further information, see http://www.world-exchanges.org/home/index.php/news/worldexchange-news/wfe-ioma-releases-2015-derivatives-market-survey.
}

prices. Therefore, all options are allowed to contribute. ${ }^{10}$

- Option filters: Similar to the previous reasoning, all options are allowed to contribute.

- Roll-over times: Our empirical analysis shows that on more than $90 \%$ of the sample days, most actively traded options are the ones with the nearest time to maturity. Even on the day of the expiry, this observation does not change. Therefore, options with the closest maturity are used until the very last day of their trading life.

\section{Data and empirical results}

As mentioned earlier, our sample covers the period between October 1, 2013 and February 28, 2017 (858 trading days). All data related to Borsa Istanbul (options, futures, underlying index etc.) comes directly from the stock exchange's database. We obtain the rest of the variables from Bloomberg Database.

First, we start by displaying the time-series behaviour of the VBI in Fig. 1. This figure contains the actual VBI series, and also displays the smoothed trend component of the VBI obtained via Hodrick and Prescott (1997) filter, which helps us to eliminate noise and focus on the big picture. ${ }^{11}$ The filtered series shows that VBI follows a short cyclical pattern from the end of 2013 till early 2016 taking values between 20 and 25. However, by mid-2016, this pattern is broken and VBI follows a declining trend till the end of our sample period, reaching to

\footnotetext{
${ }^{10}$ On each day, Borsa Istanbul introduces index options with strike prices limited from below and above by $\pm 20 \%$ of the last trading day's settlement price. So, in practice, we are implicitly using a similar version of the range rule by the Hong Kong Stock Exchange (see Table 1).

11 The idea of the H-P filter is the following: Let $y_{t}$ for $t=1,2, \ldots, T$ denote the logarithms of a time series variable. The series $y_{t}$ is made up of a trend component, denoted by $\tau$ and noise $c$ such that $y_{t}=\tau_{t}+c_{t}$. Given an adequately chosen positive $\lambda$, there is a trend component that solves $\min _{\tau}\left(\sum_{t=1}^{T}\left(y_{t}-\tau_{t}\right)^{2}+\lambda \sum_{t=2}^{T-1}\left[\left(\tau_{t+1}-\tau_{t}\right)-\left(\tau_{t}-\tau_{t-1}\right)\right]^{2}\right)$. The first term of the equation is the sum of the squared deviations $d_{t}=y_{t}-\tau_{t}$ which penalizes the noise. The second term is a multiple $\lambda$ of the sum of the squares of the trend component's second differences. This second term penalizes variations in the growth rate of the trend component.
} 


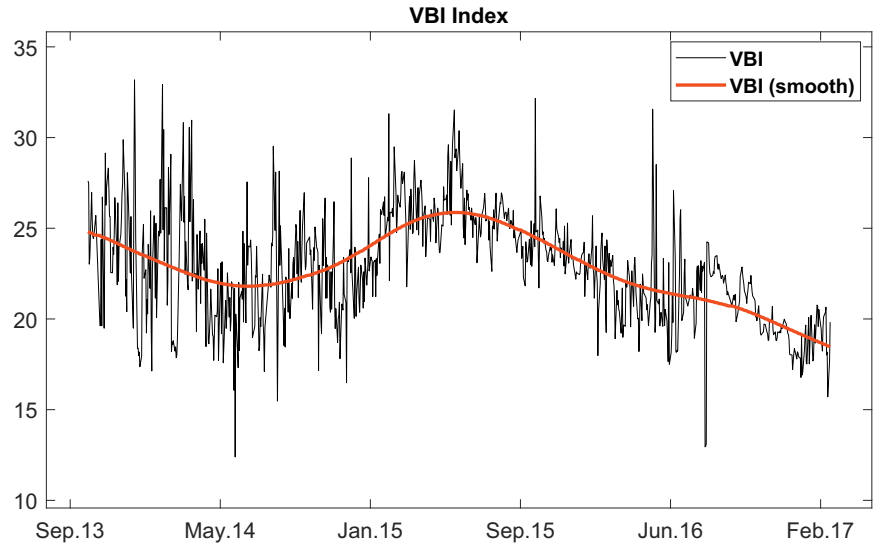

Fig. 1. Implied volatility index of Borsa Istanbul (VBI) between October 2013 and February 2017. Black curve denotes the actual series while the red curve is the smoothed trend obtained by Hodrick-Prescott filter. (For interpretation of the references to color in this figure legend, the reader is referred to the web version of this article.)

values below 20 .

\subsection{Descriptive analysis of the VBI}

Table 2 gives us the main descriptive statistics of the VBI level series and its daily changes calculated as $\ln \left(V B I_{t}\right)-\ln \left(V B I_{t-1}\right)$.

According to Panel A of Table 2, the average daily VBI level and return values are 22.79 and $-0.04 \%$ respectively, showing that VBI tends to decrease in our sample period. VBI ranges from a minimum of 12.39 up to a maximum 33.18, with a daily standard deviation of 3.07. On the other hand, daily VBI returns have seen a maximum and minimum of $61 \%$ and $-58 \%$ respectively, showing that VBI can change widely following consecutive days. This is also validated by its high unconditional standard deviation of 0.11 . Both levels and returns are positively skewed, whereas VBI returns exhibit a relatively high kurtosis of 7.81, compared to the kurtosis value of VBI levels, which is 3.14. Skewness and kurtosis coefficients indicate that return series are far from normally distributed, which is also shown by the Jarque-Bera test (JB) that rejects the null hypothesis of normality for the daily return series at $1 \%$ significance level. However, same can not be said for the VBI level series itself.

Panel A of Table 2 also presents the results of the conventional stationarity tests for the VBI level and return series (unit root tests contain a constant). Augmented Dickey-Fuller (ADF) test rejects the null hypothesis of unit root for the return series at the $1 \%$ significance level. Similarly, Kwiatkowski-Phillips-Schmidt-Shin (KPSS) test can not

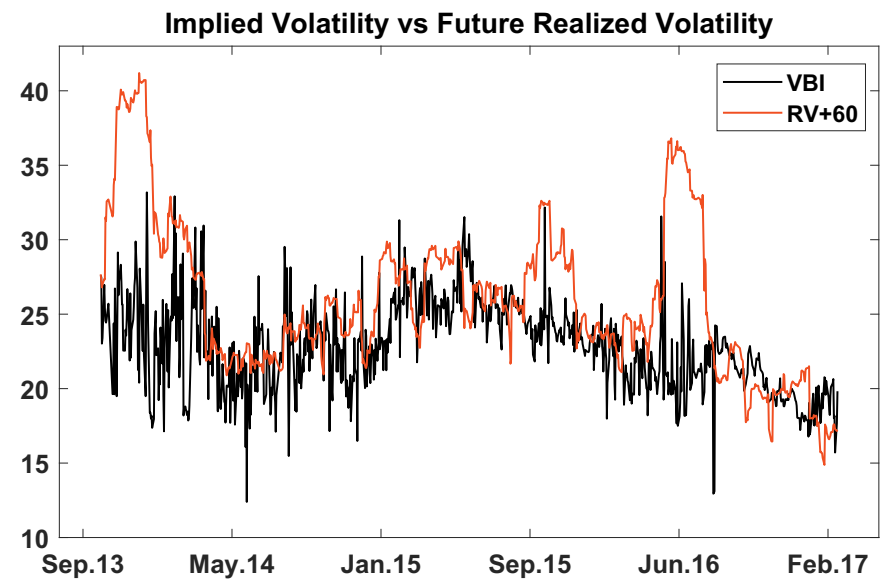

Fig. 2. Implied volatility vs realized volatility in the next 60 calendar (44 trading) days.

reject the stationarity of the VBI returns. On the contrary, VBI level series is found to be non-stationary by both tests, which is not surprising as expected.

Further, we examine the existence of serial correlation and heteroskedasticity in returns via Ljung-Box Q-test and ARCH-LM test respectively using lags from 1 to 10 . Accordingly, return series exhibit the ARCH behaviour and is serially correlated like many other financial return series.

\subsection{Forecasting realized volatility}

One of the main concerns regarding the implied volatility indices is that whether they add value to forecasting future realized volatility or not. In this part, we try to answer this question.

VBI aims to reflect the 60 calendar days ahead realized volatility (RV) which is estimated in the following way:

$R V_{t+60}=\sqrt{\frac{30}{22} \times \frac{252}{43} \times \sum_{i=1}^{44}\left(r_{t+i}-\frac{1}{44} \sum_{j=1}^{44} r_{t+j}\right)^{2}}$.

In this representation, $r_{t}$ is the equity index return on day $t, \sqrt{30 / 22}$ is an adjustment factor to make return volatility conform to the same 22-trading-day basis to which VBI is calibrated.

To start with, we present Fig. 2 to show how these two variables are related. A rough look at Fig. 2 shows that, except for the spikes in future realized volatility around October-November 2013 and May-June

Table 2

Descriptive properties of the VBI.

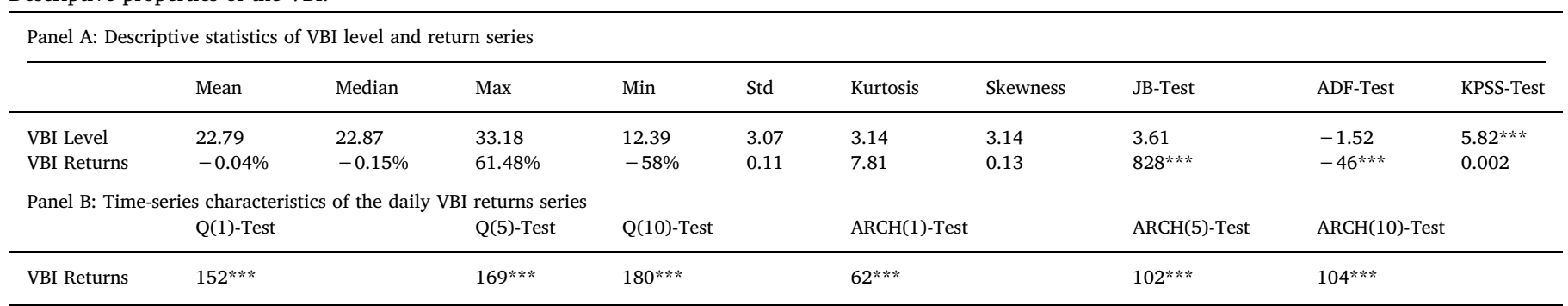

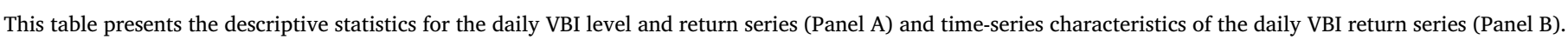

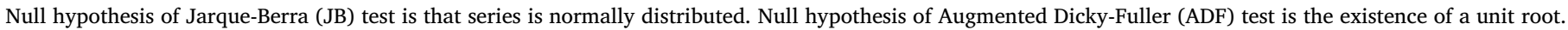

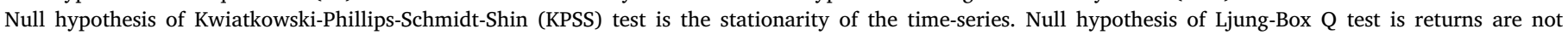
autocorrelated. Null hypothesis of ARCH-LM test is the absence of ARCH effect. In both panels, *, ** and *** denote $10 \%$, $5 \%$ and $1 \%$ significance level. 
2016, the two variables seem to be consistently correlated with each other. $^{12}$

We then estimate the following Eqs. (3) and (4). ${ }^{13}$

$\ln \left(R V_{t+60}\right)=\alpha+\beta_{1} \ln \left(V B I_{t}\right)+\varepsilon_{t}$

$\ln \left(R V_{t+60}\right)=\alpha+\beta_{1} \ln \left(V B I_{t}\right)+\beta_{2} \ln \left(R V_{t}\right)+\varepsilon_{t}$

According to Christensen and Prabhala (1998), if VBI contains at least some information about future realized volatility, coefficient $\beta_{1}$ in Eq. (3) should be statistically significant. Furthermore, the significance should be preserved even when we control for the past realized volatility as in Eq. (4). The estimations of these equations are performed via iteratively re-weighted least squares with a bisquare weighting function to get robust statistics, and the results are given in Table 3.

Results for Eq. (3) show that implied volatility as proxied by VBI contains important information regarding future realized volatility, since its estimated coefficient is around 0.61 and highly significant. Accordingly, a higher (lower) implied volatility today implies a higher (lower) realized volatility within the next 60 calendar days in the equity market of Borsa Istanbul.

Moreover, the results for Eq. (4) indicate that: (i) volatility is persistent since the lagged realized volatility is significant, and (ii) implied volatility can still explain future realized volatility even when the past realized volatility is taken into account. In this specification, the coefficient of VBI slightly decreases from 0.61 to 0.43 with a slight loss of significance, but yet it still has a stronger explanatory power than the past realized volatility both in terms of coefficient magnitude and significance. $^{14}$

To support the argument above, we further estimate the root mean square errors (RMSE) when VBI and historical realized volatility are separately used as the predictor of future realized volatility. In this setup, RMSE is calculated as the following:

$R M S E=\sqrt{\frac{\sum_{t=1}^{N}\left(\hat{y}_{t}-y_{t}\right)^{2}}{N}}$

where $\hat{y}_{t}$ is the 60 calendar days ahead realized volatility on day $t$. In the first case, we take $y_{t}$ to be the VBI level on day $t$, and in the second case, $y_{t}$ is taken to be the realized volatility in the past 60 calendar days (which is known as the naive case). According to these assumptions, RMSE values are 5.82 and 5.94 for VBI and historical volatility respectively, where the former value is significantly lower than the latter. This finding and the results in Table 3 show the superiority of our implied volatility index VBI over the past realized volatility in forecasting the future realized volatility of Turkish market. Furthermore, employing the modified version of RMSE given in Eq. (6) shows that using the implied volatility and the past realized volatility together improves the forecasting results dramatically. In this setup, the $\alpha$ that minimizes the Eq. (6) is found to be 0.5149 leading to an $\operatorname{RMSE}(\alpha)$ value of 4.82 which is significantly smaller than both of the previous

\footnotetext{
12 The two spikes in future realized volatility can be explained as the following: First, during December 17-25, 2013, Turkey was confronted with a corruption investigation that turned the political agenda upside down. The investigation involved several key people in the Turkish government, family members of cabinet ministers and various businessmen. Second, on July 15th, 2016, a coup d'état was attempted in Turkey against state institutions, including the government and President Erdogan. Both events created serious turmoil in turkish equity market, echoing for weeks. Since they could not be anticipated prior to their occurrences by the market participants, the difference between implied volatility and future realized volatility widens in the relevant periods.

13 The natural log-transformation of variables in these equations are performed to get stationary series.

${ }^{14}$ At this stage, it would be possible to use more advanced techniques, but we wanted to make the results clear for the general audience and also make it comparable to the previous studies.
}

Table 3

Realized volatility forecasting power of VBI.

\begin{tabular}{|c|c|c|c|}
\hline & $\alpha$ & $\beta_{1}$ & $\beta_{2}$ \\
\hline Eq. (3) & $\begin{array}{l}1.3137^{\text {k.kek }} \\
(9.823)\end{array}$ & $\begin{array}{l}0.6095^{1 * * *} \\
(14.218)\end{array}$ & $\begin{array}{l}- \\
-\end{array}$ \\
\hline Eq. (4) & $\begin{array}{l}0.6721^{\text {. }} \\
(4.872)\end{array}$ & $\begin{array}{l}0.4344^{1} \\
(10.357)\end{array}$ & $\begin{array}{l}0.3562^{\text {1. }} \\
(10.192)\end{array}$ \\
\hline
\end{tabular}

In this Table, Eq. (3) stands for $\ln \left(R V_{t+60}\right)=\alpha+\beta_{1} \ln \left(V B I_{t}\right)+\varepsilon_{t}$ whereas Eq. (4) represents $\ln \left(R V_{t+60}\right)=\alpha+\beta_{1} \ln \left(V B I_{t}\right)+\beta_{2} \ln \left(R V_{t}\right)+\varepsilon_{t}$. Estimations are performed via iteratively re-weighted least squares with a bisquare weighting function. The values in the parentheses are $t$-stats.

*** Denotes 1\% significance level.

individual scores.

$R M S E(\alpha)=\sqrt{\frac{\sum_{t=1}^{N}\left(R V_{t+60}-\alpha \times V B I_{t}-(1-\alpha) \times R V_{t}\right)^{2}}{N}}$

\subsection{Relation with the domestic and global financial indicators}

In this section, we examine how VBI is related with major domestic and global financial indicators. For this purpose, we consider the daily data of the followings as the domestic/country related variables: (a) BIST30 Equity Index, (b) local currency government bond yields with 10 years to maturity (TR10Y YIELD), (c) equally weighted Euro-USD basket value against Turkish Lira (FX BASKET), (d) CDS written on USD denominated Turkish sovereign bonds with 5 years to maturity. For the global financial indicators, we select: $(e)$ Brent crude oil, $(f)$ gold, $(g)$ yield of U.S. treasuries with 10 years to maturity (US10Y YIELD), $(h)$ MSCI World stock market index, (i) financial conditions of the U.S. (FCON US), ( $j$ ) financial conditions of the eurozone (FCON EU), $(k)$ implied volatility index of the U.S. (VIX), and (l) implied volatility index of the eurozone (V2X). All data are obtained from Bloomberg.

Fig. 3 shows how VBI and the abovementioned variables evolve during our sample period. Even though the relation between VBI and the others seem ambiguous from this figure, opposite movements of VBI and the BIST30 Index stands out among the rest.

For further examination, we analyse the correlations between daily changes in VBI and the other variables. For all indicators except financial conditions, we use log-returns to measure daily changes. Since financial conditions indices might take negative values, we use first differences for those variables.

First row in Panel A of Table 4 presents the unconditional correlation values between VBI and the domestic indicators. Accordingly, VBI is negatively correlated with the underlying equity index. The correlation between the two is -0.118 and significant at $1 \%$ level. This observation is especially important since it provides diversification benefits through adding a long spot implied volatility index position to the benchmark equity index portfolio (Daigler \& Rossi, 2006). ${ }^{15}$ Qualitatively, this negative correlation is consistent with the earlier works on this subject (Whaley, 2000; Simon, 2003; Giot, 2005; Bollerslev, Litvinova, \& Tauchen, 2006; Hibbert, Daigler, \& Dupoyet, 2008). However, the correlation level in our case is relatively low compared to the findings of others. Indeed, Bugge et al. (2016) face a similar situation when they construct the implied volatility index for the Norwegian equity market. They attribute the results to the lack of option market liquidity in the Norwegian options market. Due to this illiquidity problem, implied volatility index can not absorb information very well, and the relevance of the implied volatility to the corresponding equity index stays limited.

\footnotetext{
${ }^{15}$ In addition to the diversification benefits created by this situation, Black (2006) suggests that the skew and excess kurtosis of many hedge fund strategies can be eliminated by a small long exposure to spot implied volatility index.
} 

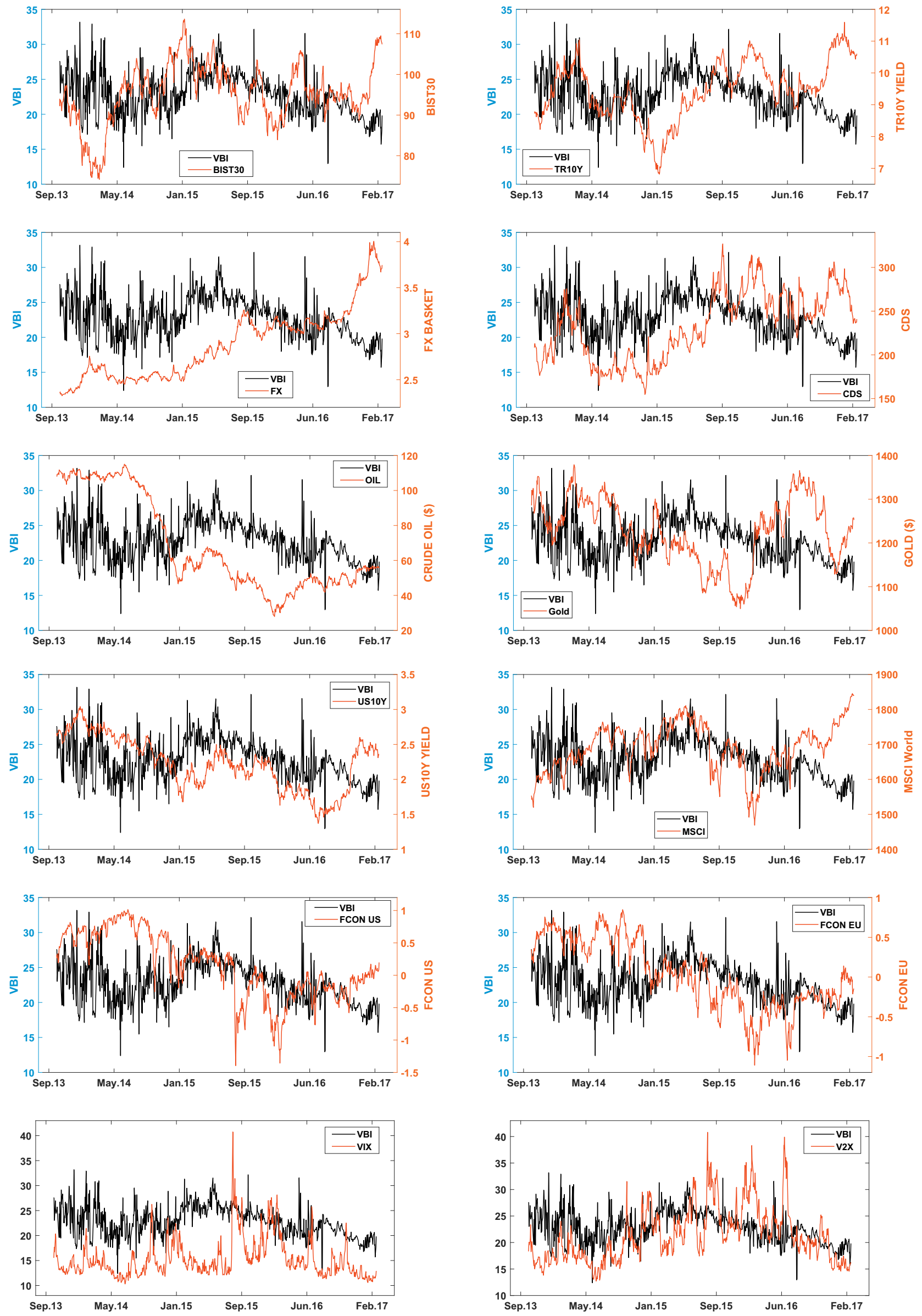

Fig. 3. VBI and its relation with several domestic and global financial indicators. 
Table 4

Unconditional and conditional correlations between VBI and major financial indicators.

Panel A: Correlations with Turkey related financial indicators

\begin{tabular}{|c|c|c|c|c|c|c|c|c|}
\hline & & & BIST30 & $\mathrm{FX}$ & CDS & TR10Y Yield & & \\
\hline & & VBI (uncond.) & $-0.118^{\text {witk }}$ & $0.061^{*}$ & $0.056^{*}$ & $0.085^{* k \hbar k}$ & & \\
\hline & & $p$-Value & 0.001 & 0.081 & 0.090 & 0.013 & & \\
\hline & & VBI (cond.) & $-0.128^{* * * i k}$ & $0.073^{*}$ & $0.087^{*}$ & $0.111^{\text {wakik }}$ & & \\
\hline & & $p$-Value & 0.001 & 0.075 & 0.062 & 0.009 & & \\
\hline \multicolumn{9}{|c|}{ Panel B: Correlations with global financial indicators } \\
\hline & Crude oil & Gold & MSCI World & US10Y Yield & FCON US & FCON EU & VIX & V2X \\
\hline VBI (uncond.) & -0.044 & -0.045 & $-0.076^{\text {t*k }}$ & -0.017 & -0.017 & $-0.064 *$ & 0.021 & 0.051 \\
\hline$p$-Value & 0.197 & 0.193 & 0.027 & 0.624 & 0.615 & 0.061 & 0.552 & 0.142 \\
\hline VBI (cond.) & -0.051 & -0.038 & $-0.081^{* *}$ & -0.037 & -0.017 & $-0.077^{* k k}$ & 0.016 & 0.063 \\
\hline$p$-Value & 0.176 & 0.195 & 0.013 & 0.566 & 0.600 & 0.049 & 0.633 & 0.111 \\
\hline
\end{tabular}

Note:

* Denotes $10 \%$ significance level.

** Denotes 5\% significance level.

*** Denotes 1\% significance level.

Besides the equity market index, VBI is significantly and positively correlated with the country related financial indicators. Although the correlation levels are low, they indicate that there is a positive contemporaneous relation between VBI and FX, CDS, and bond markets. This is, in fact, an expected property of an "investor fear gauge" in an emerging market. Emerging markets are infamous for their currency and debt crisis, and Turkey is no exception. When such crises occur, we observe massive capital outflows leading to depreciation of the local currency, decrease in bond prices and an increase in the country default risk; all supporting the signs of the abovementioned correlations.

On the other hand, we do not observe significant correlations between VBI and the global financial indicators, except the MSCI World stock market index and the financial conditions of the eurozone (see the first row in Panel B of Table 4). The latter shows that as the financial conditions surrounding the eurozone improve (worsen), investor fear in Turkish equity market decreases (increases). This finding is not surprising as eurozone is the largest trading partner of Turkey. In addition, equity market investors from eurozone hold more than $20 \%$ of the total market capitalization of Borsa Istanbul in their portfolios. ${ }^{16}$ Contrarily, significant negative correlation between VBI and the MSCI index can be explained by the following: Our sample overlaps with the turbulent periods of the eurozone sovereign bond crisis, and in the meantime Turkey also had specific political problems. Both cases might lead stock market investors in Turkey (and also in other emerging markets) to search for alternative risky assets in the global financial arena. If that is the case, capital outflow from these emerging markets would cause a depreciation in both the benchmark equity indices and the local currencies against the USD, which would increase the investor fear in these countries, hence a rise in the corresponding implied volatilities. If the new address of the capital is developed markets such as the North America or the U.K., then MSCI World index would increase due to the relatively larger weights of these developed markets in the calculation of this index. Therefore, the correlation would be negative.

It is interesting to see that VBI is not significantly correlated with two of the most important commodities in the world, crude oil and gold. Furthermore, insignificant correlations between VBI and the financial conditions of the U.S., VIX and V2X present us a puzzling case even though their signs make sense. One reason might be the illiquidity of the options market in Turkey. Accordingly, as argued by Bugge et al. (2016), information can not be captured well by the VBI hence the

\footnotetext{
$\mathbf{1 6}$ https://www.mkk.com.tr/project/MKK/file/content/Bilgi $\ \% 20$ Merkezi \%20Dosyalar $\ \%$ C4\\%B1 $\% 2$ FBorsa $\backslash \% 20$ Trendleri $\ 20$ Raporu $\backslash \% 2 F B o r s a \backslash$ \%20Trendleri $\% 20$ Raporu $\% 20 X X I$.
}

Table 5

Parameter estimates for the VAR(1) model.

\begin{tabular}{|c|c|c|c|c|c|c|}
\hline & \multicolumn{2}{|l|}{$V B I_{t}$} & \multicolumn{2}{|l|}{$V I X_{t}$} & \multicolumn{2}{|l|}{$V 2 X_{t}$} \\
\hline & Coefficient & $t$-Stat & Coefficient & $t$-Stat & Coefficient & $t$-Stat \\
\hline$V B I_{t-1}$ & $-0.420^{* \ldots * k}$ & -13.53 & -0.006 & -0.24 & -0.023 & -1.20 \\
\hline$V I X_{t-1}$ & $0.171^{k *}$ & 2.28 & 0.001 & 0.02 & $0.276^{k * * k}$ & 8.22 \\
\hline$V 2 X_{t-1}$ & -0.056 & -0.85 & -0.016 & -0.33 & $-0.219^{* * * *}$ & -5.48 \\
\hline constant & -0.0006 & -0.17 & -0.0003 & -0.11 & -0.0002 & -0.08 \\
\hline
\end{tabular}

Note:

$* *$ Denotes 5\% significance level.

*** Denotes 1\% significance level.

correlations remain insignificant. Another argument might be the asynchronicity in the calculation of these variables. VBI is calculated at the end of the day when the Turkish market is closed, whereas U.S. related variables are still traded/calculated at that time. Notwithstanding that the dates are the same, some of the global variables reflect a few hours ahead information since we use end-of-day data for each variable. Therefore, a lead-lag scheme should be considered, which we will do later in this paper.

While presenting the descriptive statistics, we showed that daily changes in VBI exhibit powerful ARCH effects, like many other financial return series. One concern may be that the $\mathrm{ARCH}$ effect is influencing the correlation levels and the previous findings are not valid. To deal with this concern, we estimate the conditional correlations between the daily changes in VBI and the other indicators via constant conditional correlation model of Bollerslev (1990). In doing so, we use a standard GARCH $(1,1)$ model for the univariate volatility of the considered variables. ${ }^{17}$ Conditional correlation levels are presented in the third rows in both Panel A and Panel B of Table 4. New correlation levels show that not only are the previous findings valid, but they are also stronger in terms of correlation levels and the statistical significance of these correlations. Therefore, the findings are robust.

\subsection{Implied volatility spillovers}

In this part, we examine the spillover effects of the implied volatility of the U.S. equity market, as proxied by VIX, and the implied volatility

\footnotetext{
17 To save space, we do not report the results of the GARCH estimations here. However, they are available upon request.
} 

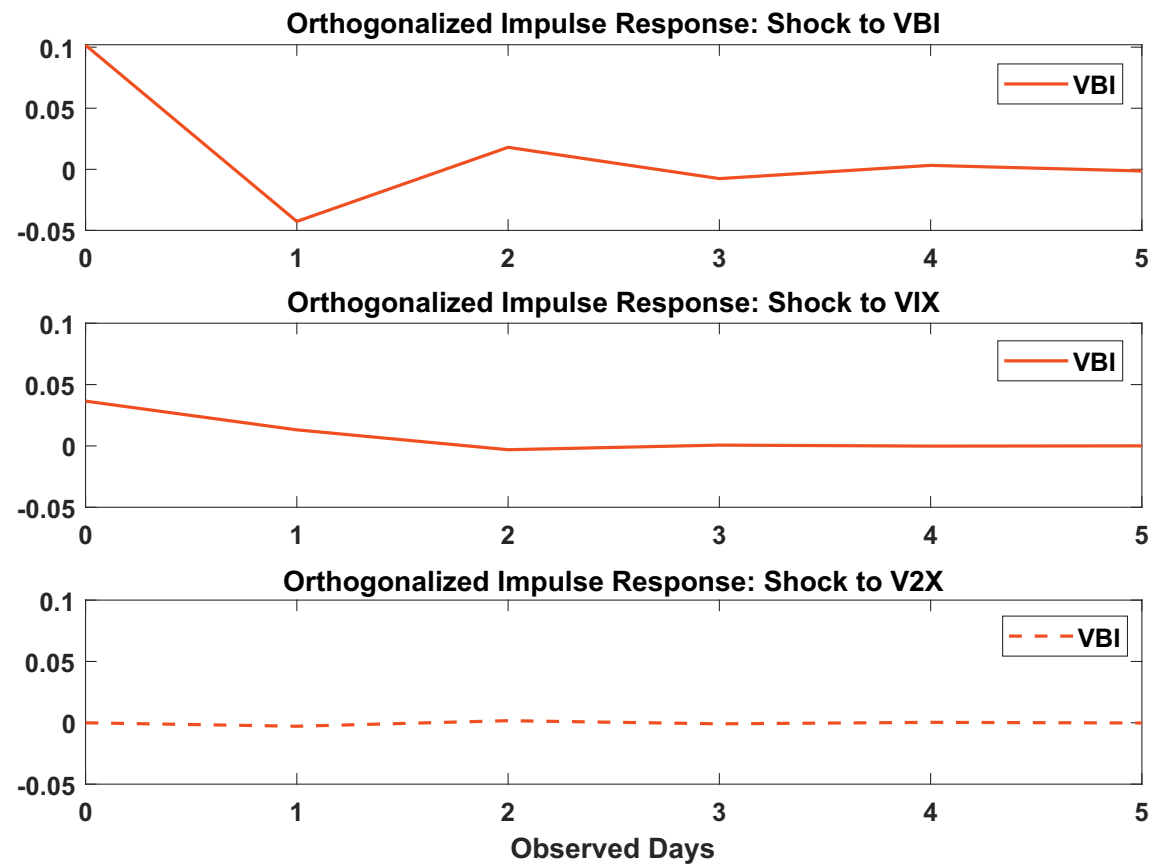

Fig. 4. Generalized impulse responses of VBI to the shocks. Dashed line denotes insignificance.

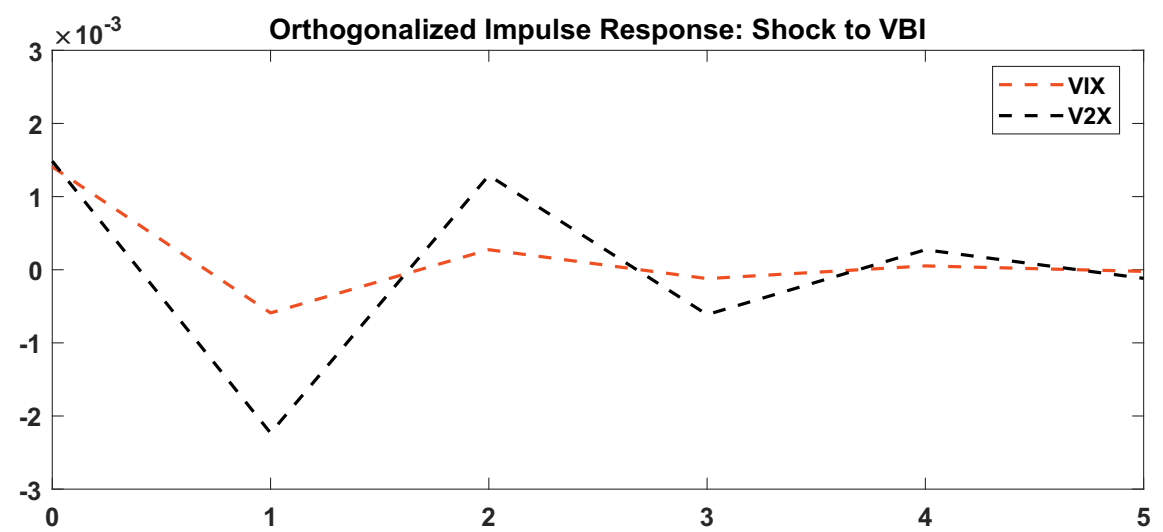

Fig. 5. Generalized impulse responses of VIX and V2X to the shocks to VBI. Dashed line denotes insignificance.

of the eurozone equity markets, as proxied by $\mathrm{V} 2 \mathrm{X}$, on the implied volatility of the Turkish equity market, as proxied by VBI. Bottom right corner of the Fig. 3 presents how these indices vary over time during our sample period. As an emerging market, it is natural to observe that implied volatility level of the Turkish equity market is higher than the other two on average. Indeed, daily mean value of VBI is 22.79 whereas the mean value is 15.27 and 21.27 for VIX and V2X, respectively. Higher daily mean level of V2X compared to VIX can be explained by the fact that considerable part of our sample period overlaps with the turmoil of the eurozone sovereign debt crisis.

In order to examine the relation between implied volatilities of the selected markets, we use the vector autoregressive analysis $(\operatorname{VAR}(p))$ and the generalized impulse response functions (GIRF) on the daily logreturns of VBI, VIX and V2 $\times$. Both methodologies are commonly used for capturing the dynamic structure of interrelated time series and they suit very well to our use in this case. The appropriate lag length of the VAR model is determined by the Bayesian Information Criteria which is found to be 1 . The estimated parameters of the VAR model are given in Table 5 and Figs. 4-5 display the impulse responses of implied volatilities to the shocks in the system.

According to Table 5, VBI is significantly effected both by its lagged values and the VIX, whereas lagged V2X has no such a significant effect on VBI. Accordingly, an increase in VIX today has a significant impact on VBI in the same direction tomorrow. In addition to that, there is no spillover from other implied volatilities to VIX, but lagged VIX has a significant positive effect on V2X too. As expected, VBI has no significant explanatory power on the changes in the other two indices.

Similar conclusion can be extracted from the impulse response analysis in Figs. 4-5. According to Fig. 4, shocks to the implied volatility of the U.S. equity market has a significant impact on the implied volatility of the Turkish equity market in the same direction, lasting up to 2 days. Whereas, we do not observe such a significant effect from the eurozone equity markets to the Turkish equity market. On the other hand, Fig. 5 shows the effects of shocks to VBI on the implied volatilities in the U.S. and eurozone equity markets. As expected, no significant impact is observed here. ${ }^{18}$

\footnotetext{
${ }^{18}$ A recent study by Sensoy, Ozturk, and Hacihasanoglu (2014) finds similar results up to some point. In their study, authors construct a financial conditions index for Turkey, and then examines its relation with the financial conditions in U.S. and the eurozone via VAR and GIRF analysis. According to their results, even though financial conditions of both the U.S. and the eurozone have significant impact on the financial conditions of Turkey, the former has a higher effect.
} 
In Section 4.3, we have shown that the correlation between daily changes in VBI and the financial conditions of the eurozone is significant. However, the same could not be said for the correlation between VBI and the financial conditions of U.S., and also for the correlation between VBI and VIX. One of the possible explanations for this case was the asynchronicity between Turkish and the U.S. equity markets. We are using the daily market closing values of these indices, therefore even though we are on the same calendar day, the U.S. and Turkish data cannot be technically characterized as contemporaneous. On the other hand, this problem is negligible in the case of Turkey and eurozone since the time difference between the two regions is only $1 \mathrm{~h}$. VAR and GIRF analysis seem to verify this explanation as the lagged VIX has a significant impact on VBI, whereas lagged V2X has no such significant effect.

\section{Conclusion}

We describe the CBOE's model-free methodology for constructing the widely popular implied volatility index VIX. Although this methodology is straightforward in theory, it is not an easy job to estimate it empirically due to the fact that there are several variables to be proxied. Accordingly, one needs to determine parameters and rules such as the calculation frequency, reference option prices, forward price levels, risk-free rates, option filters and roll-over times.

In this paper, we first review the popular implied volatility indices around the world that uses the same CBOE methodology. We give details about their parameter selections along with their reasonings. Then we modify this selection process to make it compatible with an emerging market, Turkey, where the options market is illiquid and immature. Applying this procedure to Borsa Istanbul's data, we introduce VBI, the implied volatility index of Turkish equity market.

We use VBI to obtain several important empirical results: First, we show that VBI is a strong predictor of the future realized volatility of the underlying equity index. Even when we control for historical (realized) volatility, the predictive power of VBI remains highly statistically significant. Moreover, compared to historical (realized) volatility, VBI is a stronger predictor both in terms of coefficient magnitude and statistical significance. On top of that, using both of them at the same time improves the forecasting process dramatically. Second, we examine the relation between VBI and several important domestic and global financial indicators. We find that VBI is significantly correlated with country related indicators such as Turkish equity market index, foreign exchange rate against Turkish lira, local currency government bond yields, and CDS written on the USD denominated sovereign bonds of Turkey. However, the correlations become insignificant when we consider global financial indicators such as crude oil, gold, U.S. treasuries with 10 years maturity, financial conditions of U.S., and the implied volatilities of U.S. and eurozone equity markets. The only exceptions are the MSCI global stock market index and the financial conditions of eurozone in which the correlations are both significantly negative. Third, we investigate the implied volatility spillovers among Turkish, U.S. and eurozone equity markets. Vector auto-regression and impulse response analysis reveal that implied volatility spills over from the U.S. equity market to eurozone and Turkish equity markets, but not the other way around. As expected, implied volatility of the Turkish equity market has no spillover effect on the other two markets.

As the data becomes available, further research might include estimating implied volatility indices for those emerging markets without such official indices. Implied volatility indices have been shown to be important tools for investors, policy-makers and academics due to their forward-looking property. Introducing these indices to a wider range of markets might improve asset and risk management, and provide effective policy-making in those countries.

\section{Appendix A. Supplementary Materials}

Table A. 1

Most popular implied volatility indices calculated by the new VIX methodology.

\begin{tabular}{lll}
\hline Volatility Index & Stock Exchange & Underlying Index \\
\hline VIX & CBOE & S\&P500 \\
VDAX & Deutsche Borse & DAX30 \\
VFTSE & Euronext (London) & FTSE100 \\
VCAC & Euronext (Paris) & CAC40 \\
VSTOXX & Eurex & EUROSTOXX 50 \\
VXJ & NIKKEI & NIKKEI225 \\
VSMI & Swiss Exchange & SMI \\
VKOSPI & Korean Exchange & KOSPI200 \\
VHSI & Hong Kong Stock Exchange & HSI \\
VAEX & Euronext (Amsterdam) & AEX \\
VBEL & Euronext (Brussels) & BEL20 \\
NIFVIX & NSE & NIFTY \\
S\&P/TSX60 VIX & Montreal Exchange & S\&P TSX60 \\
S\&P/ASX200 VIX & Australian Stock Exchange & XJO \\
Taiwan VIX & TAIFEX & TAIEX \\
VXD & CBOE & DJIA \\
VXN & CBOE & NASDAQ100 \\
VXV* & CBOE & S\&P500 \\
RVX & CBOE & RUSSELL2000 \\
\hline
\end{tabular}

Note: All the indices above measure 30-calendar day implied volatility with the exception VXV, which measures 91-calendar day implied volatility. 


\section{References}

Andersen, T. G., Bondarenko, O., \& Gonzalez-Perez, M. T. (2015). Exploring return dynamics via corridor implied volatility. Review of Financial Studies, 28, 2902-2945.

Areal, N. (2008). FTSE-100 Implied volatility index. SSRN Working Paperhttps://doi.org/ $10.2139 /$ ssrn. 1102135.

Black, F., \& Scholes, M. (1973). The pricing of options and corporate liabilities. Journal of Political Economy, 81, 637-654.

Black, K. (2006). Improving hedge fund risk exposures by hedging equity market volatility, or how the VIX ate my kurtosis. Journal of Trading, 1, 6-15.

Bollerslev, T. (1990). Modeling the coherence in short-run nominal exchange rates: A multivariate generalized ARCH mode. Review of Economics and Statistics, 72, 498-505.

Bollerslev, T., Litvinova, J., \& Tauchen, G. (2006). Leverage and volatility feedback effects in high-frequency data. Journal of Financial Econometrics, 4, 353-384.

Bugge, S. A., Guttormsen, H. J., Molnar, P., \& Ringdal, M. (2016). Implied volatility index for the Norwegian equity market. International Review of Financial Analysis, 47, 133-141.

Carr, P., \& Wu, L. (2006). A tale of two indices. Journal of Derivatives, 13, 13-29.

CBOE. (2003). White paper - CBOE volatility index. https://www.cboe.com/micro/vix/ vixwhite.pdf.

Christensen, B. J., \& Prabhala, N. R. (1998). The relation between implied and realized volatility. Journal of Financial Economics, 50, 125-150.

Daigler, R. T., \& Rossi, L. (2006). A portfolio of stocks and volatility. Journal of Investing,
$15,99-106$.

Giot, P. (2005). Relationships between implied volatility indexes and stock index returns. Journal of Portfolio Management, 31, 92-100.

Gonzalez-Perez, M. T., \& Novales, A. (2011). The information content in a volatility index for Spain. Journal of the Spanish Economic Association, 2, 185-216.

Grover, R., \& Thomas, S. (2012). Liquidity considerations in estimating implied volatility. Journal of Futures Markets, 32, 714-741.

Hibbert, A., Daigler, R., \& Dupoyet, B. (2008). A behavioral explanation for the negative asymmetric return-volatility relation. Journal of Banking \& Finance, 32, 2254-2266.

Hodrick, R., \& Prescott, E. C. (1997). Postwar U.S. business cycles: An empirical investigation. Journal of Money, Credit, and Banking, 29, 1-16.

Sensoy, A., Ozturk, K., \& Hacihasanoglu, E. (2014). Constructing a financial fragility index for emerging countries. Finance Research Letters, 11, 410-419.

Simon, D. P. (2003). The Nasdaq volatility index during and after the bubble. Journal of Derivatives, 11, 9-24.

Siriopoulos, C., \& Fassas, A. (2012). An investor sentiment barometer - Greek Implied Volatility Index (GRIV). Global Finance Journal, 33, 77-93.

Tzang, S. W., Hung, C. H., Wang, C. W., \& Shyu, D. S. D. (2011). Do liquidity and sampling methods matter in constructing volatility indices? Empirical evidence from Taiwan. International Review of Economics \& Finance, 20, 312-324.

Whaley, R. E. (2000). The investor fear gauge. Journal of Portfolio Management, 26, 12-17.

Wu, D., \& Liu, T. (2018). New approach to estimating VIX truncation errors using corridor variance swaps. Journal of Derivatives, 25, 54-70. 